\title{
MAKNA SYARAT DAN UNSUR SILEK DESA KUBU GADANG
}

\author{
Mita Rosaliza ${ }^{1}$, Muhammmad Fajar Vierta Wardhana ${ }^{2}$ Risdayati $^{3}$ \\ Universitas Riau \\ mita.rosaliza@lecturer.unri.ac.id ${ }^{1}$, fhajarvierta@gmail.com², \\ risdayati@lecturer.unri.ac.id ${ }^{3}$
}

\begin{abstract}
The martial art of silat in Minangkabau, which is usually called silek, has its own uniqueness in terms of terms and movements. Silek in Minangkabau is a legacy from the Minangkabau ancestors that still exists and develops today. The requirements that must be possessed in this silat include cloth, knives, sewing needles, mirrors, rice and money that have meaning in this silat tradition. In addition, there are other elements in these martial arts which also have meaning in terms of movement, clothing and place of implementation. This study focuses on the meaning of the terms and movements used in the silek of Tuo gunuong in Kubu Gadang village. The informants in this study are traditional elders and people who still practice silat as a martial art and understand the terms and meanings of the movement.
\end{abstract}

Keywords: Meaning, Silek Tuo Gunuang, Kubu Gadang Village

\section{Pendahuluan}

Orang Minangkabau merupakan salah satu dari antara kelompok etnis utama bangsa Indonesia yang menempati pulau Sumatera lebih tepatnya Sumatera bagian tengah dan menjadikannya sebagai kampung halamannya, yang merupakan provinsi Sumatera Barat. Sekalipun secara statistik orang Minangkabau hanya berupa kira-kira 3\% dari seluruh peduduk
Indonesia, mereka adalah kelompok etnis utama yang ke-empat sesudah orang Jawa, Sunda, dan Madura, sedangkan di pulau Sumatera sendiri mereka merupakan kelompok etnis yang terbesar dengan jumlah penduduk seperempat dari seluruh penduduk pulau Sumatera (Naim, 1979).

Ciri khas yang tentunya masih melekat dari budaya Minangkabau yaitu 
sebuah kesenian, dimana di setiap daerah yang ada di Indonesia memiliki keunikannya masing-masing mengenai sebuah kesenian, salah satunya yang terdapat di Minangkabau Propinsi Sumatera Barat sendiri terutama. Di Minangkabau mempunyai suatu seni kebudayaan khas yang di wariskan oleh nenek moyang orang Minangkabau yang berada sejak tanah atau bumi Minangkabau ada. Seni yang ada di Minangkabau sendiri itu bermacammacam bentuk serta berbagai macam nama dalam setiap seni yang ada di daerah tersebut.

Pada umumnya seni bela diri silat yang biasa disebut silek di Minangkabau disesuaikan dengan nama daerah atau tempat aliran silek itu berkembang, hal itu dalam dilihat seperti: Silek Lintau, Silek Pauah, Silek Kumango, Silek Pangian, Silek Sitaralak, Silek Sungai Patai, Silek Sugiridiek, Silek Luncua, Silek Sungai Pagu, Silek Sinua, Silek Koto Anau, Silek Pasisia, Silek Bayang, Silek Paninjauan dan Silek Gunuang. Selain dari apa yang telah di sampaikan di atas ternyata silek ini ada juga nama aliran silek yang diambil dari alam atau melihat alam beserta makna dan fungsi dalam aliran silek itu sendiri seperti: Silek Gayuang Salacuik, Silek Ulu Ambek, Silek Unggan, Silek Jantan dan Batino, Silek Balam, Silek Buayo Lalo, Silek Rantau, Silek Sicabiak Kapan, Silek Harimau, Silek Alang, Silek Lamo Alif, Silek Buah Tarok, Silek Ilau, dan masih banyak lagi nama dan jenis aliran silek yang ada di Minangkabau (Putri, 2015).

Silek ini mempunyai peranan, yang pertama itu silek sebagai seni penjaga diri atau bela diri dan dinamakan dengan silek. Kedua silek ini sebagai permainan anak Nagari yang dinamakan dengan pancak sedangkan dalam bahasa Indonesia itu dinamakan dengan pencak, dimana pancak ini fungsinya sebagai seni pertunjukan. Pancak dalam silek itu merupakan satu tahapan awal dalam mempelajari silek. Di dalam dunia silek Minangkabau para pemain silek itu dinamakan dengan pasilek disebut dengan pandeka (pendekar), sedangkan sebutan untuk pemain pancak disebut dengan 
anak sasian atau anak silek karena umumnya yang mempelajari pancak adalah remaja dan anak-anak. Seorang pandeka Minangkabau mempunyai filosofi dalam etika, musuah indak dicari, jikok basuo pantang diilakkan, dalam artian "musuh tidak dicari, kalau bertemu uuntuk pantang dielakan atau di hindarkan" (Navis, 1984).

Dari sekian banyaknya jenis aliran silek yang terdapat di Minangkabau, serta disetiap daerahnya memiliki nama aliran silek yang berbeda-beda juga, di Kota Padang Panjang lebih tepatnya di kecamatan Padang Panjang Timur Provinsi Sumatera Barat, terdapat satu aliran bela diri silek yang dinamakan dengan silek tuo Gunuang yang terletak di ka Nagarian (negeri) Gunuang. Silek tuo Gunuang merupakan aliran bela diri yang ada dan pertama kali di Nagari Gunuang, aliran silek ini tidak di ketahui kapan dan tahun berapa adanya, tetapi sebuah aliran itu ada dan bisa di katakana sejak nenek moyang orang Nagari Gunuang ada dan di kembangkan sampai sekarang ini. Silek tuo Gunuang merupakan bela diri yang mematikan dan bukan untuk di pertontonkan ke khalayak ramai atau umum, akan tetapi silek tuo Gunuang hanya digunakan untuk penjagaan diri dan untuk membela diri saja.

Di Nagari Gunuang tepatnya di Desa Kubu Gadang Kelurahan Ekor Lubuk Kecamatan Padang Panjang Timur selain mempunyai aliran bela diri yang khas dan mematikan ternyata juga memiliki sebuah kesenian pertunjukan yang dimana asal-usulnya di ambil atau di angkat dari metode silek tuo Gunuang.

Desa Kubu Gadang di jadikan sebagai Desa wisata sejak tahun 2015 yang di lakukan oleh Dinas kebudayaan yang bermula dari pelatihan yang di berikan oleh Dinas Pariwisata setempat serta dorongan dari masyarakat setempat untuk mengangkat potensi daerah tersebut. Dari hasil tersebut, muncul sebuah permainan rakyat dan kesenian baru yang juga di adaptasi atau di modifikasi dari aliran silek Minangakabau dan merupakan aliran silek khas Nagari tersebut yaitu silek tuo Gunuang. 
Metode yang di ambil dari silek tuo

Gunuang adalah sasaran (tempat latihan) yang dimana silek tuo Gunuang melakukan latihan kalau seandainya sudah cukup mahir dalam hal gerakan dan untuk melatih keseimbangan kemudian tempat latihan atau sasaran tersebut di basahi dengan air agar licin dan berguna untuk melatih kuda-kuda si pasilek serta melatih keseimbangannya. Kemudian metode tersebut di ambil dan diubah dan di lakukan di sawah yang sudah siap di panen, hal ini di ambil dan di lakukan di sawah karena Desa Kubu Gadang memiliki hamparan sawah yang cukup luas dan mayoritas dari penduduknya bertani padi. Itulah yang mendasari kenapa silek ini di lakukan di sawah serta gerakan dan metodenya di ambil dari silek tuo gunuang dan yang sudah dimodifikasi untuk kebutuhan pertunjukan dan kebutuhan untuk promosi desa Kubu Gadang tersebut.

Melihat dari fenomena yang telah dipaparkan diatas, penulis merumuskan masalah sebagai berikut: Bagaimana makna syarat dan Gerakan silek tuo gunuang di desa Kubu Gadang

Kelurahan Ekor Lubuk Kecamatan Padang Panjang Timur Provinsi Sumatera Barat.

\section{Konsep dan Teori}

Berbicara tentang Makna tidak lepas dari perbincangan Blumer secara rinci membahas hubungan antara pikiran seseorang, dirinya, dan masyarakat. Bagi Blumer simbolik bertumpu pada tiga premis yaitu:

1. Individu merespon suatu situasi simbolik, mereka merespon lingkungan termasuk obyek fisik (benda) dan obyek sosial (perilaku manusia) berdasarkan media yang dikandung komponen-komponen lingkungan tersebut bagi mereka.

2. Makna adalah produk interaksi sosial, kerean itu makna tidak melihat pada obyek, melainkan dinegosiasikan melalui penggunaan bahasa, negosiasi itu dimungkinkan karena manusia mampu mewarnai segala sesuatu bukan hanya objek fisik, tindakan atau peristiwa 
(bahkan tanpa kehadiran obyek fisik, tindakan atau peristiwa itu) namun juga gagasan yang abstrak.

3. Makna yang interprestasikan individu dapat berubah dari waktu ke waktu, sejalan dengan perubahan situasi yang ditemukan dalam interaksi sosial, perubahan interprestasi dimungkinkan dengan dirinya sendiri (Sunarto, 2004).

Tindakan tentang pembelajaran makna dan simbol, serta aksi dan interaksi sebagian besar melahirkan apa yang disebut "kebudayaan". Eksistensi silek Tuo Gunuang dipengaruhi oleh tindakan-tindakan yang dipilih indvidu berdasarkan tindakan yang dimaknainya melalui gerakan dan makna dari setiap apa yang aktor peragakan. Selain dari gerakan makna dari basilek Tuo Gunuang juga dapat dilihat dari tempat, benda, serta pakaian yang dipakai dalam tradisi tersebut. Makna silek Tuo Gunuang yang dipahami dan di internalisasi masyarakat di Desa Kubu Gadang akan mempengaruhi tindakan individu untuk melakukan interaksi tertentu yang berarti tetap menjaga eksistensinya atau bisa pula sebaliknya.

Interaksi yang ada dalam masyarakat sebagai bentuk kerja sama diri sang aktor dengan sang aktor lainnya merupakan fokus tatanan makna simbolik pada skala mikro dan msyarakat itu sendiri pada skala makro. Esensinya adalah interaksi sebagai diri sang aktor akan melahirkan tatanan masyarakat yang didalamnya terdapat hubungan timbal balik (komunikasi) melalui simbol yang muncul berdasarkan setting interaksi yang khas, bukan setting ketegori universal yang bersumber semata dari luar (Elbadiansyah, 2014).

\section{Metode}

Penelitian ini dilakukan di Desa Kubu Gadang (dahulunya jorong) yang terletak di jalan Haji Miskin, Kelurahan Ikua Lubuak (Ekor Lubuk) Kecamatan Padang Panjang bagian Timur, Nagari Gunuang (Gunung). Peneliti memilih lokasi di Desa Kubu Gadang karena di Desa tersebut terdapat adanya tradisi Silek Tuo Gunuang yang sudah ada sejak lama 
dan peneliti tertarik untuk mengangkat tradisi di desa itu.

Penelitian Kualitatif deskriptif di maksudkan untuk membuat generalisasi dari jawaban-jawaban dari para informan (Nugroho, 2015). Informan penelitian menjadi informan yang akan memberikan berbagai informasi yang diperlukan selama proses penelitian. Informan penelitian ini meliputi dua macam yaitu: (1) informan kunci (Key Informan), yaitu mereka yang mengetahui dan memiliki informasi pokok yang di perlukan dalam penelitian, (2) informan yaitu mereka yang melakukan Silek Tuo Gunuang dan mengetahui makna syarat dan Gerakan dan juga yang terlibat secara langsung dalam interaksi sosial yang diteliti (Suyanto, 2005).

Untuk memperoleh informasi dan data yang mendukung penelitian ini maka penulis akan meminta keterangan kepada orang yang dituakan atau orang yang mengetahui secara mendalam mengenai Silek Tuo Gunuang dan orang yang terlibat langsung serta melakukannya. Informan penelitian yang telah tercermin dalam fokus penelitian ditentukan secara purposive (Moleong, 2002), subyek penelitian ini menjadi informan yang akan memberikan berbagai informasi yang diperlukan selama proses penelitian.

Informan yang diambil dalam penelitian ini dipilih berdasarkan kriteria yang dimaksudkan peneliti diantaranya yaitu:

1. (Key Informan) yang tahu mengenai segala sesuatu tentang pelaksanaan Silek Tuo Gunuang, yang terdiri dari: Datuak (Datuk), Pemuka Adat dan pelatih Silek Tuo Gunuang.

2. (Informan) Orang yang mengetahui dan yang memahami Silek Tuo Gunuang.

\section{Pembahasan}

Silek bagi orang Minangkabau adalah Silaturrahmi, maksud dari kata silaturrahmi adalah dimana orang Minangkabau berpegangan hidup kepada Adat basandi Syara', syara' basandi Kitabullah, yang artinya orang Minangkabau memiliki adat yang berpandangan kepada Agama yaitu 
Agama Islam, serta dari Agama Islam kemudian berpedoman kepada Kitabullah atau Al-qur'an, maka masyarakat Minangkabau sangat berpegang teguh kepada Adat atau tradisi yang telah di warisi oleh nenek moyang mereka (Navis, 1984).

Dalam hal ini Silek itu dahulunya adalah bela diri yang di wariskan oleh mamak ke anak kamanakan, dimana dahulunya orang Minangkabau khususnya yang laki-laki itu belajar silek di Surau, dalam artian surau dimana anak laki-laki di didik serta di ajarkan untuk mengaji. Mengaji bukan berarti hanya sekedar mengaji akan tetapi mengaji adalah dimana mengkaji apa yang telah di baca di Al-qur'an atau yang di jelaskan makna serta tujuan dari apa yang kita kaji dan tujuannya untuk apa, itulah mengapa anak laki-laki di Minangkabau di haruskan untuk ke surau karena disana mereka akan di ajarkan tentang kehidupan akhirat. Setelah apa yang di dapatkan dari surau tadi, barulah mereka belajar silek dimana di surau tidak hanya di ajarkan tentang akhirat saja akan tetapi di surau mereka juga di ajarkan tentang kehidupan dunia. Maksud dari ini semua, setelah anak-anak di ajarkan di surau atau didik tentang agama, dan mereka telah mendapatkan semua yang di ajarkan atau makna yang terkandung di dalam AlQur'an dan mereka sudah memiliki ilmu untuk akhirat barulah mereka di ajarkan ilmu Silek untuk menjaga diri mereka serta sanak saudara mereka.

Laki-laki Minangkabau yang bisa Silek juga di artikan sebagai Parik Paga dalam Nagari, yang di maksud dengan Parik Paga dalam Nagari adalah sebagai pelindung untuk kampung serta sanak saudaranya. Hal ini di maksudkan ketika seorang laki-laki di Minangkabau bisa Silek dia akan menjadi pelindung buat kampung atau tempat tinggal dia, karena di kampung tersebut terdapat sanak saudara mereka yang perempuan, disitulah fungsi laki-laki di Minangkabau untuk belajar silek.

Di Minangkabau bisa di katakan perempuan yang bisa silek itu tidak ada atau bahkan jarang di jumpai, akan tetapi di Kelurahan Ekor Lubuk (Nagari 
Gunuang) Tepatnya di Desa Kubu sebuah gerakan yang di mainkan seperti Gadang terdapat satu orang pasilek wanita yang bernama Inyiak Upiak pencak kalau dalam bahasa Minangnya adalah mancak-mancak atau hanya Palatiang (Data Penelitian, 2019) yang merupakan pasilek satu-satunya wanita Minang. Inyiak Upiak Palatiang di kenal dengan Silek Tuo Gunuang, hal ini di karenakan keluarga dari beliau adalah orang pasilek. Inyiak Upiak Palatiang bisa belajar silek karena rumpun atau Pusat dari silek itu sendiri adalah dari keluarga atau keturunan beliau yang ada di Nagari Gunuang.

Silek Tuo Gunuang merupakan aliran Silek yang ada atau pertama di Nagari Gunuang tersebut, hal ini lah yang menjadikan Silek Tuo Gunuang menjadi aliran silek yang ada di nagari Gunuang ini. Silek Tuo Gunuang ini merupakan aliran silek yang tidak bisa di pertontonkan atau di tampilkan di depan umu atau di khalayak ramai, karena sifat dari Silek Tuo Gunuang ini adalah mematikan atau membunuh. Di Minangkabau itu terdapat perbedaan dalam hal Basilek dan Silek, dalam artiannya kalau Basilek itu adalah hanya sekedar gerakan untuk sebuah atraksi yang untuk di pertunjukan dalam kesenian, sedangkan Silek itu adalah mati dan bunuh dalam artian silek ini hanya untuk bela diri dan bukan untuk ajang yang di pertontonkan seperti halnya atraksi dalam kesenian.

Silek Tuo Gunuang sendiri itu gerakannya tidak bisa untuk di gambarkan dan tidak bisa untuk di perlihatkan ke khalayak umum, di karenakan sifat dari Silek Tuo Gunuang sendiri adalah mati dan bunuh, Silek Tuo Gunuang ini hanya sebagai bela diri saja dan bukan untuk sebuah atraksi untuk pertunjukkan. Karena Silek Tuo Gunuang bukan untuk di pertontonkan ke umum, maka anak Nagari atau Desa Kubu Gadang merevisi atau memodifikasi Silek Tuo Gunuang menjadi sebuah kesenian yang dapat di pertontonkan dan di saksikan oleh khalayak ramai dengan mengambil metode dari latihan dari Silek Tuo Gunuang yang berupa Lacah atau 
tempat licin yang seperti lumpur. Lacah itu sendiri merupakan metode dari latihan Silek Tuo Gunuang yang berguna untuk melatih dan menguatkan kuda-kuda kaki untuk daya tahan kuda-kuda kaki tersebut.

Adapun Syarat yang diwajibkan untuk dilengkapi oleh setiap orang yang akan memainkan silek bukanlah diperintahkan tanpa alasan. Keseluruhannya memiliki makna dan filosofi tersendiri serta sudah dipercayai sejak generasi terdahulu. Mulai syarat yang terkecil sampai terbesar memiliki fungsi dan makna yang berbeda-beda. Kesepakatan makna antara setiap unsur yang terlibat dalam silek tuo gunuang sudah menjadi persetujuan dari seluruh unsur tersebut yang kemudian diwajibkan kepada generasi selanjutnya untuk melengkapi. Berikut rincian makna sari syarat untuk basilek Tuo Gunuang.

\section{a. Kain}

Syarat pertama yakni kain. Ada beberapa warna yang biasa digunakan sebagai syarat perlengkapan silek. Warna- warna tersebut ada dua jenis yakni terang dan gelap. Namun, tidak semua orang yang bersilek harus memakai warna cerah ataupun gelap saja. Meskipun identiknya adalah putih dan hitam akan tetapi jenis warna lain boleh digunakan asal sopan dan tidak mengganggu.

\section{b. Pisau}

Silek tuo gunuang juga menggunakan peralatan berupa pisau. Akan tetapi, pisau tidak bermakna untuk membunuh atau melukai seseorang. bahwa makna syarat dari pisau adalah .di ibaratkan seperti pisau yang tajam, itulah makna syarat pisau tadi yang mengibratkan kita seperti pisau, walaupun kita tajam, kita tidak boleh melukai orang lain, dan seberapa pintarnya kita atau pandainya ilmu kita, kita tidak boleh merusak atau menganiaya orang lain, kita harus merasakan dulu betapa sakitnya kena pisau tersebut, sebelum melukai orang lain kita harus merasakan dulu kalau kita yang terlukai oleh diri kita sendiri, intinya rasakan dulu ke diri kita, sakit terasa jangan lakukan ke orang lain. 


\section{c. Jarum Jahit}

Unsur berikutnya yakni jarum. Hampir sama seperti pisau, jarum memiliki filosofi tersendiri dan bukan dimaksudkan untuk melukai seseorang. Makna yang terkandung di dalamnya yakni mengenai ketajaman ilmu yang dimiliki oleh seseorang bukanlah untuk menyakiti orang lain bahwa jarum jahit ini memiliki makna hampir sama dengan pisau, dimana pisau tadi untuk ke tajaman sedangkan makna dari jarum jahit ini adalah untuk keruncingan yang tidak boleh gunanya untuk menusukan ke orang lain, dan fungsinya juga sama dari pisau tadi.

\section{d. Cermin}

Cermin memiliki makna tersendiri yang mengajarkan kita untuk tidak sombong terhadap orang lain dengan ilmu maupun keahlian yang kita miliki. Masih banyak orang lain yang harus dihormati keberadaannya. Ilmu yang dimiliki oleh diri kita bukanlah ilmu yang tidak dimiliki oleh orang lain, sehingga berlaku sombong akan ilmu yang kita miliki bukanlah cerminan keteladanan.

\section{e. Beras dan Uang}

Syarat yang biasa diharuskan untuk lengkap ada sejumlah uang dan beras. Hal ini dimaksudkan untuk menghargai para guru yang telah memberikan ilmunya kepada kita yang sedang mempelajari silek. Penghargaan tersebut secara filosofi untuk memberikan biaya makan dan minum kepada sang guru.

Untuk lebih jelasnya dapat dilihat dalam table 1.1 mengenai makna syarat dalam melakukan silek Tuo Gunuang dari para informan berikut ini : 
Tabel 1.1 Makna Syarat Silek Tuo Gunuang

\begin{tabular}{|c|c|c|c|c|c|c|}
\hline \multirow{2}{*}{ No } & \multirow{2}{*}{ Informan } & \multicolumn{5}{|c|}{ Intisari Jawaban Tentang Makna Syarat Silek Tuo Gunuang } \\
\hline & & Kain & Pisau & Jarum Jahit & Cermin & Beras dan Uang \\
\hline 1 & $\begin{array}{l}\text { Angku } \\
\text { Jufriadi, } \\
\text { DT. Sati }\end{array}$ & $\begin{array}{l}\text { syarat dalam silek } \\
\text { tuo Gunuang } \\
\text { sendiri tidak ada } \\
\text { memakai kain } \\
\text { yang bewarna } \\
\text { hitam, merah, } \\
\text { kuning di silek } \\
\text { tuo } \\
\text { hanya } r \text { ada } \\
\text { memakai kain } \\
\text { bewarna putih. } \\
\text { Hal ini menurut } \\
\text { informan } \\
\text { melambangkan } \\
\text { atau memaknai } \\
\text { kain yang } \\
\text { bewarna putih } \\
\text { tadi sebuah } \\
\text { kesucian dimana } \\
\text { baru belajar akan } \\
\text { silek dan seperti } \\
\text { itu juga jiwa atau } \\
\text { hati kita ini yang } \\
\text { belum ada } \\
\text { ternodai } \\
\text { apapun, oleh } \\
\text { memang benar- } \\
\text { benar bersih dan } \\
\text { suci seperti kain } \\
\text { tersebut. }\end{array}$ & 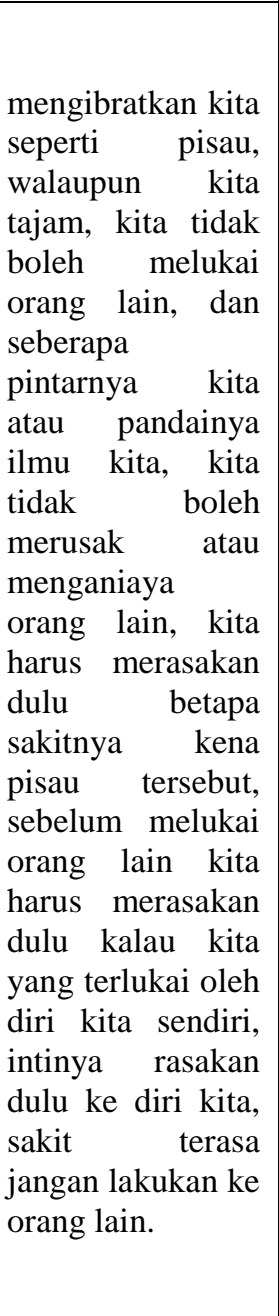 & $\begin{array}{l}\text { jarum jahit } \\
\text { ini memiliki } \\
\text { makna } \\
\text { hampir sama } \\
\text { dengan pisau, } \\
\text { dimana pisau } \\
\text { tadi untuk ke } \\
\text { tajaman } \\
\text { sedangkan } \\
\text { makna dari } \\
\text { jarum jahit } \\
\text { ini adalah } \\
\text { untuk } \\
\text { keruncingan } \\
\text { yang tidak } \\
\text { boleh } \\
\text { gunanya } \\
\text { untuk } \\
\text { menusukan } \\
\text { ke orang lain, } \\
\text { dan } \\
\text { fungsinya } \\
\text { juga sama } \\
\text { dari pisau } \\
\text { tadi. }\end{array}$ & 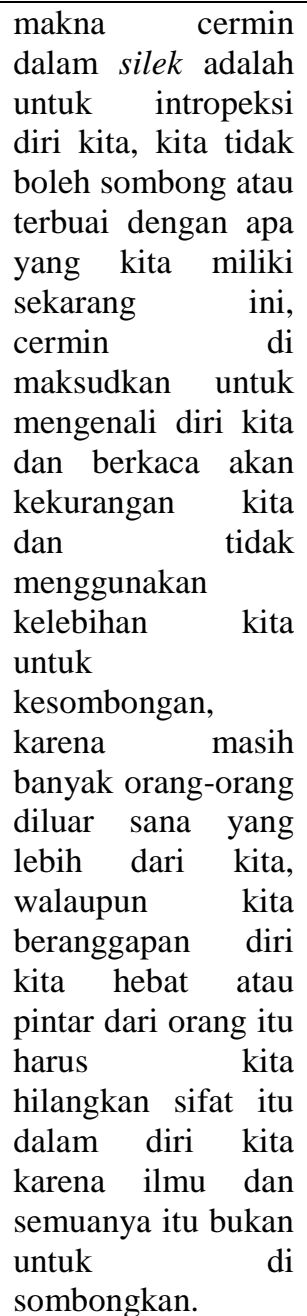 & $\begin{array}{l}\text { Istilah beras } \\
\text { sasikek jo pitih } \\
\text { satali tidak } \\
\text { hanya } \\
\text { menggambarkan } \\
\text { rasa saling } \\
\text { menghargai } \\
\text { tetapi juga } \\
\text { mengisyaratkan } \\
\text { bahwa antar } \\
\text { sesama manusia } \\
\text { untuk saling } \\
\text { berbagi kepada } \\
\text { terutama keparu- } \\
\text { mereka guru- } \\
\text { guru, } \\
\text { menghargai } \\
\text { seorang guru } \\
\text { yang dalam } \\
\text { masyarakat } \\
\text { minangkabau } \\
\text { dijunjung tinggi } \\
\text { keberadaannya. }\end{array}$ \\
\hline
\end{tabular}




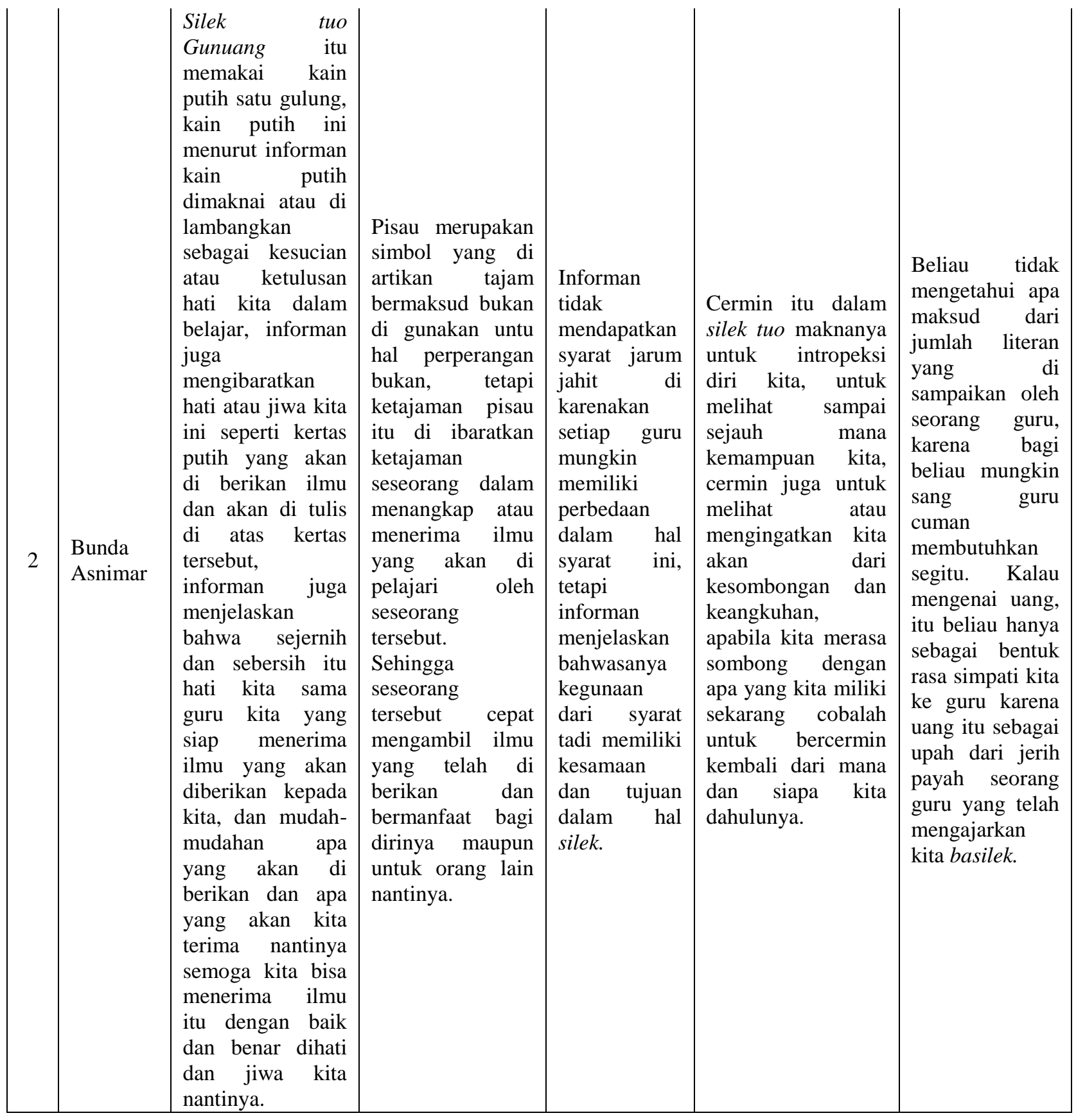




\begin{tabular}{|c|c|c|c|c|c|c|}
\hline 3 & $\begin{array}{l}\text { Gaek } \\
\text { Uncu }\end{array}$ & 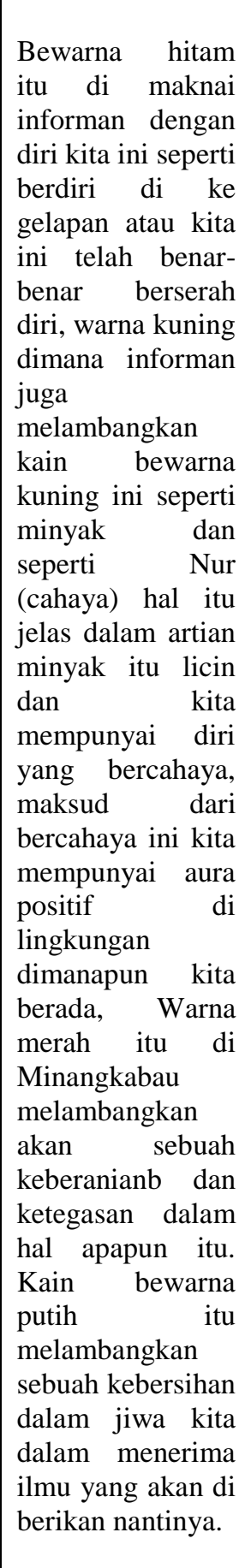 & 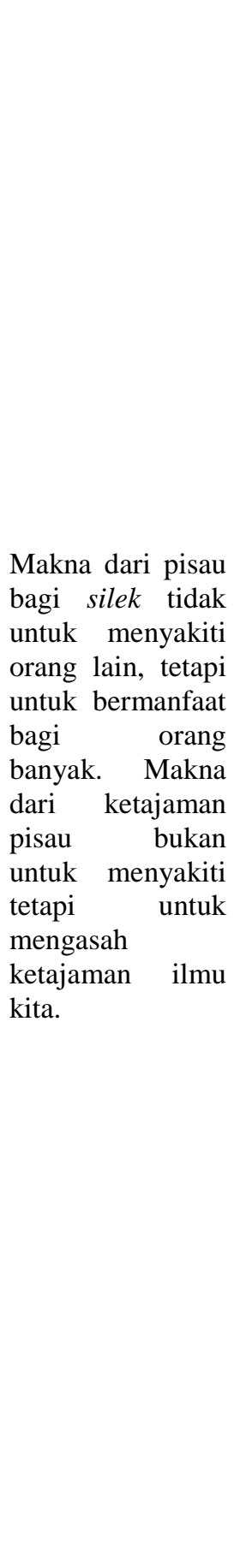 & $\begin{array}{l}\text { Makna dari } \\
\text { jarum jahit } \\
\text { ini memiliki } \\
\text { persamaan } \\
\text { dengan pisau } \\
\text { tadi, hal itu di } \\
\text { jelaskan oleh } \\
\text { informan } \\
\text { bahwasanya } \\
\text { pisau tadi di } \\
\text { maknai } \\
\text { dengan } \\
\text { tajamnya, } \\
\text { tetapi kalau } \\
\text { jarum jahit } \\
\text { ini } \\
\text { runcingnya } \\
\text { tidak untuk } \\
\text { menusukan } \\
\text { ke orang lain, } \\
\text { intinya sama- } \\
\text { sama tidak } \\
\text { untuk } \\
\text { menyakiti } \\
\text { orang lain, } \\
\text { teteapi untuk } \\
\text { terus } \\
\text { mengasah } \\
\text { tajam dan } \\
\text { rucingnya } \\
\text { kita dalam } \\
\text { menuntut } \\
\text { ilmu. }\end{array}$ & $\begin{array}{l}\text { Guna dan maksud } \\
\text { dari cermin itu } \\
\text { adalah sebagai } \\
\text { cerminan diri kita, } \\
\text { selagi kita ingat } \\
\text { akan diri kita maka } \\
\text { dengan mudahnya } \\
\text { ilmu silek ini di } \\
\text { dapatkan dan } \\
\text { gunakan dengan hal } \\
\text { positif, karena kita } \\
\text { tidak boleh } \\
\text { sombong, dan } \\
\text { apabila rita } \\
\text { sombong ilmu tadi } \\
\text { tidak ada gunanya } \\
\text { lagi. }\end{array}$ & 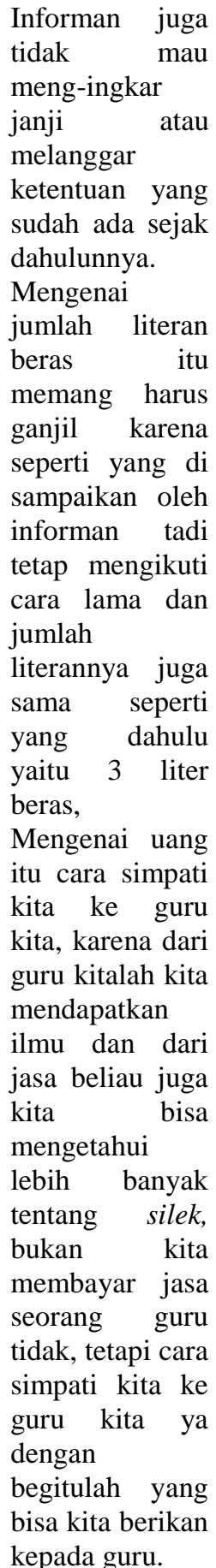 \\
\hline
\end{tabular}




\begin{tabular}{|c|c|c|c|c|c|c|}
\hline 4 & $\begin{array}{l}\text { Anduang } \\
\text { Nuzirwan }\end{array}$ & $\begin{array}{l}\text { Informan } \\
\text { mengartikan kain } \\
\text { putih sebagai kain } \\
\text { kafan buat kita, } \\
\text { hal itu di artikan } \\
\text { karena menurut } \\
\text { beliau silek itu } \\
\text { kita harus siap } \\
\text { menanggung } \\
\text { resiko apa yang } \\
\text { ada pada diri kita, } \\
\text { karena arti silek } \\
\text { sendiri kalau } \\
\text { membunuh, kalau } \\
\text { bukan kita yang } \\
\text { terbunuh berarti } \\
\text { lawan kita, } \\
\text { makanya dari itu } \\
\text { kain kafan di } \\
\text { artikan sebagai } \\
\text { kain kafan kita } \\
\text { sendiri, dan } \\
\text { mengingat akan } \\
\text { besarnya resiko } \\
\text { dalam silek ini. }\end{array}$ & 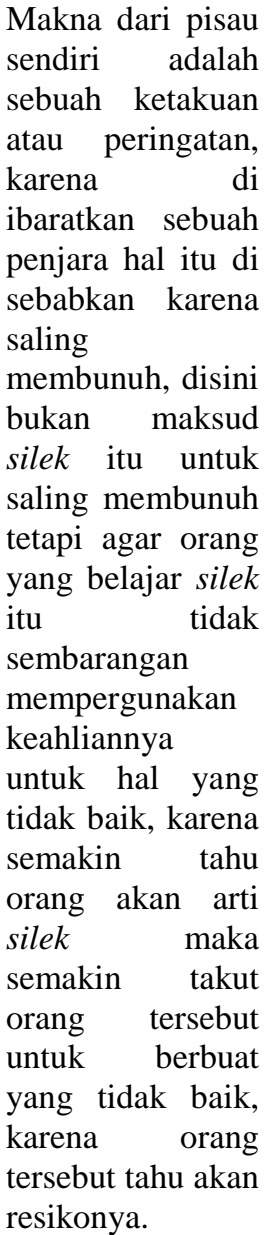 & $\begin{array}{l}\text { Menurut } \\
\text { informan } \\
\text { pisau tadi } \\
\text { sudah } \\
\text { melengkapi } \\
\text { dari jarum } \\
\text { tersebut, hal } \\
\text { tersebut di } \\
\text { karenakan } \\
\text { pisau dan } \\
\text { jarum tadi } \\
\text { memiliki } \\
\text { makna yang } \\
\text { sama, kalau } \\
\text { setiap syarat } \\
\text { yang di minta } \\
\text { itu memiliki } \\
\text { perbedaan } \\
\text { setiap } \\
\text { masing- } \\
\text { masing } \\
\text { orang, tetapi } \\
\text { memiliki } \\
\text { tujuan yang } \\
\text { sama tidak } \\
\text { untuk } \\
\text { menyakiti } \\
\text { orang lain. }\end{array}$ & $\begin{array}{l}\text { Tidak mengetahui } \\
\text { atau tidak pernah } \\
\text { memakai cermin } \\
\text { untuk sebagai } \\
\text { syarat hal ini di } \\
\text { karenakan beliau } \\
\text { juga sebagai pelatih } \\
\text { silek beliau tidak } \\
\text { ada atau tidak } \\
\text { pernah } \\
\text { menggunakan } \\
\text { cermin sebagai } \\
\text { syaratnya, informan } \\
\text { hanya } \\
\text { menyampaikan } \\
\text { syarat-syarat apa } \\
\text { yang telah beliau } \\
\text { katakan } \\
\text { sebelumnya. }\end{array}$ & $\begin{array}{l}\text { Uang dan beras } \\
\text { tadi maknanya } \\
\text { untuk ke } \\
\text { ridhoan atau } \\
\text { simpati kita } \\
\text { sama guru yang } \\
\text { telah bersedia } \\
\text { atau } \\
\text { meluangkan } \\
\text { waktunya buat } \\
\text { kita dan bentuk } \\
\text { apresiasi kita } \\
\text { kepada guru } \\
\text { dengan apa } \\
\text { yang telah guru } \\
\text { berikan kepada } \\
\text { kita tentunya. }\end{array}$ \\
\hline
\end{tabular}




\begin{tabular}{|c|c|c|c|c|c|c|}
\hline 5 & $\begin{array}{l}\text { Uda } \\
\text { Nanda }\end{array}$ & $\begin{array}{l}\text { Kain itu di artikan } \\
\text { sebagai tanda } \\
\text { bersih, yang } \\
\text { menggambarkan } \\
\text { diri kita seperti } \\
\text { kain putih yang } \\
\text { belum ada noda, } \\
\text { yang sebenar- } \\
\text { benarnya hati atau } \\
\text { jiwa kita ini } \\
\text { bersih dari } \\
\text { apapun, dan juga } \\
\text { bisa di ibaratkan } \\
\text { dengan kain kafan } \\
\text { kita, dimana kain } \\
\text { kafan ini adalah } \\
\text { untuk pakaian } \\
\text { terakhir kita, di } \\
\text { ibaratkan kalau } \\
\text { dalam silek kain } \\
\text { putih ini atau kain } \\
\text { kafan ini sebagai } \\
\text { ketakutan kita } \\
\text { untuk tidak } \\
\text { berbuat yang } \\
\text { tidak baik, karena } \\
\text { kalau salah kita } \\
\text { dalam } \\
\text { menggunakan } \\
\text { ilmu silek ini ya } \\
\text { tantangangannya } \\
\text { adalah kematian. }\end{array}$ & $\begin{array}{l}\text { Makna dari pisau } \\
\text { ini bukan untuk } \\
\text { saling menyakiti, } \\
\text { tetapi kita di } \\
\text { tuntut untuk } \\
\text { mengasah ilmu } \\
\text { kita biiar semakin } \\
\text { tajam, dan } \\
\text { seberapa hebat } \\
\text { atau tajamnya } \\
\text { ilmu kita, kita } \\
\text { tidak boleh } \\
\text { mempergunakan } \\
\text { silek untuk } \\
\text { menyakiti orang } \\
\text { lain. }\end{array}$ & $\begin{array}{l}\text { Makna dari } \\
\text { jarum jahit } \\
\text { ini hampir } \\
\text { sama dengan } \\
\text { syarat pisau } \\
\text { tadi, pisau } \\
\text { tidak di } \\
\text { gunakan } \\
\text { untuk } \\
\text { ketajamannya } \\
\text { di salah } \\
\text { gunakan, } \\
\text { sama halnya } \\
\text { dengan jarum } \\
\text { jahit yang } \\
\text { runcingnya } \\
\text { tidak di } \\
\text { gunakan } \\
\text { untuk } \\
\text { menusukan } \\
\text { ke orang, } \\
\text { tetapi tidak di } \\
\text { gunakan } \\
\text { untuk hal } \\
\text { yang negatif, } \\
\text { tetapi untuk } \\
\text { sama-sama } \\
\text { mengasah } \\
\text { ilmu yang } \\
\text { ada untuk } \\
\text { kegigihan } \\
\text { dalam } \\
\text { mencari ilmu. }\end{array}$ & $\begin{array}{l}\text { Cermin bagi silek } \\
\text { tuo adalah untuk } \\
\text { mengintropeksi diri } \\
\text { dan mengingat } \\
\text { kembali diri kita } \\
\text { kalau kita udah } \\
\text { mempunyai ilmu } \\
\text { atau untuk berkaca } \\
\text { akan diri ini supaya } \\
\text { tidak sombong dan } \\
\text { angkuh. }\end{array}$ & $\begin{array}{l}\text { Dari syarat } \\
\text { beras dan uang } \\
\text { tadi itu sama } \\
\text { dengan apa } \\
\text { yang telah di } \\
\text { sampaikan } \\
\text { beberapa } \\
\text { informan } \\
\text { sebelumnya, } \\
\text { karena menurut } \\
\text { informan makna } \\
\text { dari syarat tadi } \\
\text { sebagai bentuk } \\
\text { uang sekolah, } \\
\text { karena kita } \\
\text { menggunakan } \\
\text { jasa seorang } \\
\text { guru dan } \\
\text { sebagai bentuk } \\
\text { simpati kita } \\
\text { sebagai seorang } \\
\text { murid tentunya. }\end{array}$ \\
\hline
\end{tabular}

Sumber : data lapangan, 2019

\section{Unsur merupakan bagian terpenting}

dalam bersilek. Unsur-unsur dalam

bersilek terdiri dari gabungan antara gerakan, busana dan tempat dimana ketiganya tidak bisa ditinggalkan serta memiliki keterkaitan satu sama lain.

Silek tuo gunuang merupakan perpaduan dari berbagai macam unsur, mulai dari gerakan, busana, dan tempat yang tidak dapat dipisahkan. Kesemua unsur tersebut membentuk kesatuan yang membuat silek semakin terlihat indah untuk dipandang dan menarik minat banyak orang. Setiap unsur atau bagian yang ada pada silek memiliki akar historis yang panjang dan memiliki arti tersendiri 
bagi masyarakat khususnya pegiat silek. Pada penelitian ini penulis akan menguraikan mengenai tiga unsur pokok dalam silek tuo gunuang yang meliputi gerakan, busana, dan tempat.

\section{Gerakan}

Unsur pertama yang memgang peranan sangat penting yakni gerakan. Dikatakan penting karena unsur ini merupakan bagian paling inti dan vital. Hakekatnya silek mengutamakan gerakan dari pada yang lainnya meskipun dalam hal ini busana dan tempat merupakan bagian yang juga selalu ada dalam silek. Gerakan adalah unsur paten, seseorang tidak dapat merubahnya kecuali memodifikasi sedikit unsur yang ada dengan persetujuan dari sesepuh setempat.

\section{Tabel 2. Makna Gerakan Silek Tuo Gunuang}

\begin{tabular}{|c|c|c|c|}
\hline No & $\begin{array}{c}\text { Gambar dan Nama } \\
\text { Gerakan }\end{array}$ & Deskripsi Gerakan & Makna atau Fungsi \\
\hline 1. & Gerakan Alif & $\begin{array}{l}\text { - Gerakan Alif dalam silek tuo } \\
\text { menandakan memulai untuk } \\
\text { melangkah atau gerakan awalan } \\
\text { pembuka } \\
\text { - Gerakan alif pandangan lurus } \\
\text { kedepan (lawan) } \\
\text { - Gerakan alif tangan kanan dikepal } \\
\text { dan sedikit dekat dengan dada, } \\
\text { sikut di sejajarkan dengan baju, } \\
\text { tangan kiri berada di paha kiri dan } \\
\text { bahu bagian kiri itu menghadap } \\
\text { lurus kedepan dan di tutup rapat } \\
\text { ke dalam } \\
\text { Posisi badan lurus menyamping } \\
\text { (bahu lurus kedepan) } \\
\text { Posisi kaki kiri berada di depan } \\
\text { dan injit semata kaki dan agak } \\
\text { serong ke kanan untuk tumpuan } \\
\text { badan dan kedua kaki dibuka }\end{array}$ & $\begin{array}{l}\text { Tegak lurus, alif itu sama } \\
\text { dengan benar karena alif ini } \\
\text { berdiri dengan sendirinya. } \\
\text { Gerakan alif ini kuncinya atau } \\
\text { intinya itu demi Allah berdiri } \\
\text { dengan sendiri, gerakan alif } \\
\text { ini ada gerakan maju dan ada } \\
\text { gerakan mundurnya, karena } \\
\text { itulah alif ini bisa dikatakan } \\
\text { berdiri sendiri dan tidak ada } \\
\text { yang bisa mengatur dan } \\
\text { meragukannya. Gerakan alif } \\
\text { ini kita percaya diri maju dan } \\
\text { mundur karena Allah ta'alla, } \\
\text { dan karena Allah juga kita } \\
\text { mundur, makanya sebelum } \\
\text { kita memulai itu kita harus } \\
\text { istighfar dan karena itulah kita } \\
\text { harus mengingat Allah } \\
\text { terlebih dahulu. }\end{array}$ \\
\hline
\end{tabular}




\begin{tabular}{|c|c|c|c|}
\hline & & $\begin{array}{l}\text { sedikit kira-kira } 2 \text { kepal tangan } \\
\text { - Posisi kaki kanan menghadap ke } \\
\text { kanan dan lutut sedikit di } \\
\text { bengkokkan }\end{array}$ & \\
\hline 2. & Gerakan $B a$ & $\begin{array}{l}\text { - Gerakan } B a \text { dalam silek tuo ini } \\
\text { merupakan gerakan ke } 2 \text { atau } \\
\text { langkah ke dua } \\
\text { - Gerakan } B a \text { pandangan lurus ke } \\
\text { depan (lawan) } \\
\text { - Gerakan Ta tangan kanan dikepal } \\
\text { dan sedikit di jauhkan dengan } \\
\text { dada dan berjarak cukup dekat } \\
\text { dengan gerakan alif sebelumnya, } \\
\text { sikut tangan kanan agak di } \\
\text { majukan sedikit dan tangan kiri } \\
\text { berada di paha kiri dan bahu } \\
\text { bagian kiri agak di buka sedikit } \\
\text { dari Alif sebelumnya } \\
\text { Posisi badan lurus menyamping } \\
\text { (bahu agak di buka sedikit ke luar } \\
\text { tetapi posisi badan menyamping } \\
\text { dan sedikit menghadap kedepan } \\
\text { dari alif sebelumnya dan tetap } \\
\text { menghadap kedepan) } \\
\text { Posisi kaki kiri berada di depan } \\
\text { dan injit semata kaki dan agak } \\
\text { serong ke kanan (sedikit saja) } \\
\text { untuk tumpuan badan dan kedua } \\
\text { kaki dibuka sedikit kira-kira } 3 \\
\text { kepal tangan } \\
\text { Posisi kaki kanan menghadap ke } \\
\text { kanan dan lutut sedikit di } \\
\text { bengkokkan }\end{array}$ & $\begin{array}{l}\text { Maknanya dalam silek adalah } \\
\text { kebenaran, dimana dalam } \\
\text { gerakan ba ini kita berdiri } \\
\text { benar-benar untuk kebenaran } \\
\text { bahwasanya kita siap untuk } \\
\text { memulai awalan dengan } \\
\text { gerakan ba. Hal ini } \\
\text { bahwasanya gerakan ba itu } \\
\text { memulai karena diri kita itu } \\
\text { benar dalam hal membela diri. }\end{array}$ \\
\hline 3. & Gerakan $T a$ & $\begin{array}{l}\text { - Gerakan Ta dalam silek tuo ini } \\
\text { merupakan gerakan ke } 3 \text { atau } \\
\text { langkah untuk ke tiga kalinya } \\
\text { - Gerakan } T a \text { pandangan lurus ke } \\
\text { depan (lawan) } \\
\text { - Gerakan } T a \text { tangan kanan dikepal } \\
\text { dan di buka di jauhkan dengan } \\
\text { dada dan berjarak cukup jauh } \\
\text { dengan gerekan } B a \text { sebelumnya, } \\
\text { sikut berbetuk lurus tetapi sedikit } \\
\text { di bengkokan tangan kiri berada } \\
\text { di paha kiri dan bahu bagian kiri } \\
\text { agak di buka sedikit dari Ba } \\
\text { sebelumnya } \\
\text { Posisi badan sedikit membungkuk }\end{array}$ & $\begin{array}{l}\text { ta ini di maksudkan atau di } \\
\text { maknai dengan kita mundur } \\
\text { bukan berarti takut dan kita } \\
\text { maju bukan berarti kita ini } \\
\text { berani, cuman kita ini } \\
\text { seimbang dalam dua hal } \\
\text { tersebut. Gerakan ta ini juga } \\
\text { di maksudkan kita untuk } \\
\text { menunggu dalam artian kita } \\
\text { mundur dan maju karena } \\
\text { Allah, hal ini kita serahkan } \\
\text { semuanya kepada Allah baik } \\
\text { kita maju maupun mundur. }\end{array}$ \\
\hline
\end{tabular}




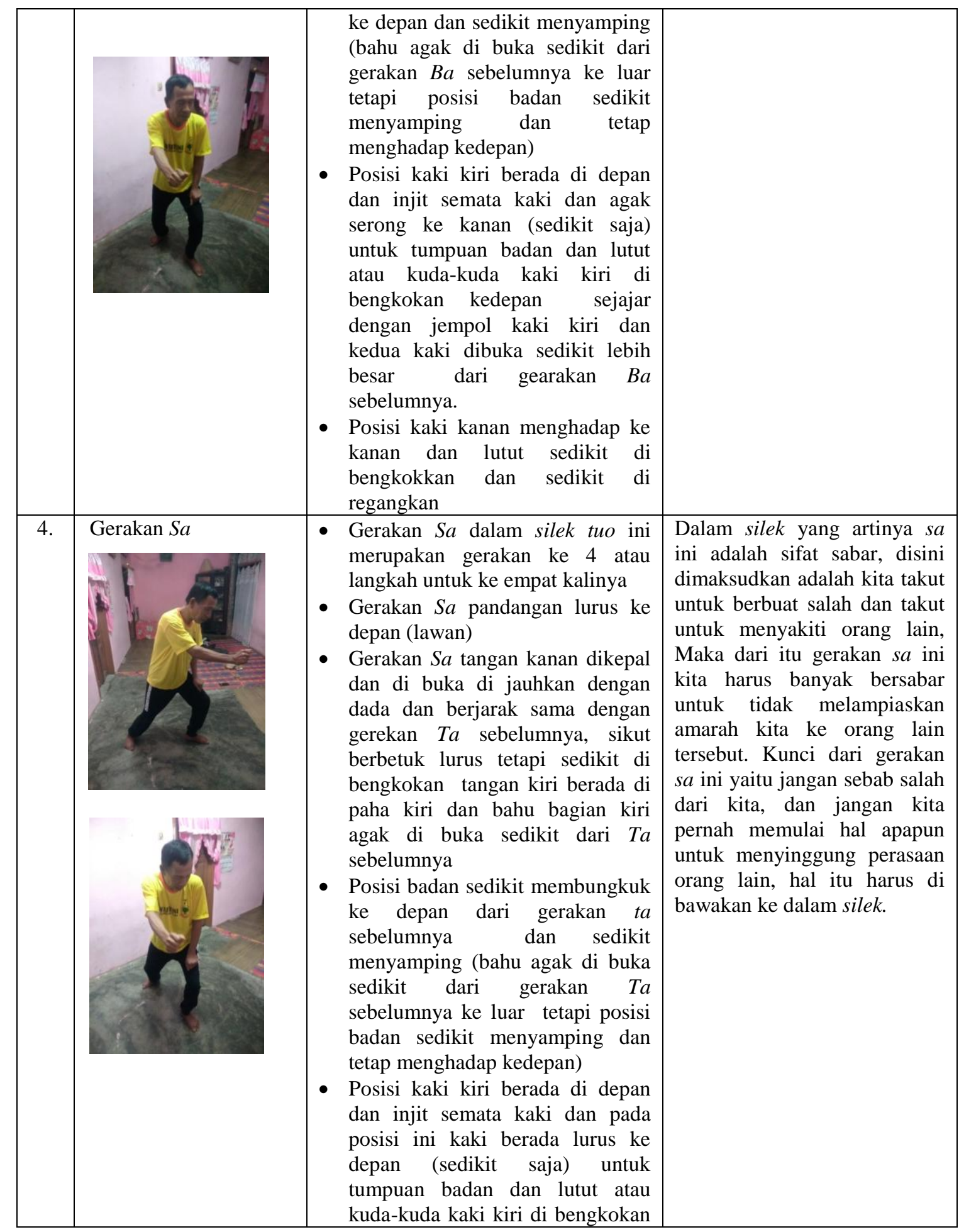




\begin{tabular}{|c|c|c|c|}
\hline & & $\begin{array}{l}\text { kedepan sejajar dengan jempol } \\
\text { kaki kiri dan kedua kaki dibuka } \\
\text { sedikit lebih besar dari gearakan } \\
\text { Ta sebelumnya. } \\
\text { - Posisi kaki kanan menghadap ke } \\
\text { kanan dan lutut sedikit di } \\
\text { bengkokkan dan Mulai renggang } \\
\text { dari gerakan } T a \text { sebelumnya }\end{array}$ & \\
\hline 5. & Gerakan $R a$ & $\begin{array}{l}\text { - Gerakan Ra dalam silek tuo ini } \\
\text { bukan termasuk ke dalam gerakan } \\
\text { langkah tetapi masuk ke dalam } \\
\text { gerakan untuk menantikan } \\
\text { serangan lawan } \\
\text { - Gerakan } R a \text { pandangan lurus ke } \\
\text { depan (lawan) } \\
\text { - Gerakan } R a \text { tangan kanan dikepal } \\
\text { dan di buka di jauhkan dengan } \\
\text { dada dan berjarak sama dengan } \\
\text { gerekan Sa sebelumnya tetapi } \\
\text { sedikit lebih tegas dari gerakan sa, } \\
\text { sikut berbetuk lurus tetapi sedikit } \\
\text { di bengkokan tangan kiri berada } \\
\text { di paha kiri dan bahu bagian kiri } \\
\text { agak di buka Sama seperti } \\
\text { gerakan Sa sebelumnya, tetapi } \\
\text { gerakan dan postur tubuh lebih } \\
\text { tegas } \\
\text { Posisi badan sedikit membungkuk } \\
\text { ke depan dari gerakan Sa } \\
\text { sebelumnya sedikit } \\
\text { menyamping (bahu sama saja } \\
\text { dengan gerakan sa sebelumnya } \\
\text { tetapi lebih di pertegas lagi kalau } \\
\text { gerakan ra ini. posisi badan } \\
\text { sedikit menyamping dan tetap } \\
\text { menghadap kedepan) } \\
\text { Posisi kaki kiri berada di depan } \\
\text { dan injit semata kaki dan pada } \\
\text { posisi ini kaki berada lurus ke } \\
\text { depan (sedikit saja) untuk } \\
\text { tumpuan badan dan lutut atau } \\
\text { kuda-kuda kaki kiri di bengkokan } \\
\text { kedepan sejajar dengan jempol } \\
\text { kaki kiri dan kedua kaki dibuka } \\
\text { sedikit lebih besar dari gearakan } \\
\text { Ta sebelumnya dan lebih tegas } \\
\text { Posisi menghadap ke }\end{array}$ & $\begin{array}{l}\text { dalam silek tuo merupakan } \\
\text { gerakan yang kita siap untuk } \\
\text { melakukan hal yang benar } \\
\text { dalam artian untuk tidak } \\
\text { menyelakai lawan kita atau } \\
\text { tidak untuk membuat lawan } \\
\text { kita cedera parah, kalau untuk } \\
\text { ke hal yang buruknya kita siap } \\
\text { untuk menyelakai lawan kita } \\
\text { ke hal yang buruk seperti } \\
\text { membuat lawan kita } \\
\text { meninggal atau bisa dengan } \\
\text { patah-patah. Makanya gerakan } \\
\text { ra ini siap untuk dalam hal } \\
\text { apapun itu. }\end{array}$ \\
\hline
\end{tabular}




\begin{tabular}{|c|c|c|c|}
\hline & & $\begin{array}{l}\text { kanan dan lutut sedikit di } \\
\text { bengkokkan dan Mulai renggang } \\
\text { dari gerakan } S a \text { sebelumnya }\end{array}$ & \\
\hline 6. & Gerakan $W a$ & $\begin{array}{l}\text { - Gerakan waw ini dalam silek tuo } \\
\text { merupakan gerakan inti yang } \\
\text { dimana di maksudkan sebagai } \\
\text { gerakan yang tidak ada maju dan } \\
\text { tidak ada mundur. } \\
\text { - Gerakan waw ini pandangan lebih } \\
\text { tegas dan siap melepaskan } \\
\text { semuanya kepada lawan kita dan } \\
\text { tatapan tajam } \\
\text { - Gerakan waw ini hampir sama } \\
\text { dengan gerakan ra, cuma bedanya } \\
\text { dari ra terletak pada ketegasan } \\
\text { dan maknanya. } \\
\text { Dalam bentuk gerakan hanya } \\
\text { berbeda posisi tubuh yang dimana } \\
\text { gerakan Ra bungkuk badan tidak } \\
\text { terlalu bungkuk tetapi gerakan } \\
\text { waw bungkuknya seperti siap } \\
\text { untuk menyerang apapun yang } \\
\text { dating } \\
\text { Kemudian dalam kepalan waw } \\
\text { lebih tegas dan lebih kuat untuk } \\
\text { melayangkan ke lawan } \\
\text { Posisi kuda-kuda waw lebih } \\
\text { matang dan lebih kuat, secara } \\
\text { keselurahan sama hanya saja beda } \\
\text { dalam posisi badan, kepalan } \\
\text { tangan, posisi kuda-kuda, dan } \\
\text { kesiapan semuanya. }\end{array}$ & $\begin{array}{l}\text { inti dari silek tuo adalah untuk } \\
\text { menantikan serangan lawan, } \\
\text { karena silek tuo tidak boleh } \\
\text { kita memulai lebih dahulu, } \\
\text { sifat dari silek tuo ini harus } \\
\text { orang yang lebih dahulu yang } \\
\text { mulainya, kalau orang sudah } \\
\text { mulai maka kita akan } \\
\text { menantikan serta memberikan } \\
\text { serangan balik kepadanya, } \\
\text { kalau sudah habis kesabaran } \\
\text { kita dan serangan kita itu } \\
\text { untuk menghabiskan atau } \\
\text { mematikan dia. Hal ini di } \\
\text { sebabkan karena silek tuo ini } \\
\text { sifatnya mematikan dan tidak } \\
\text { boleh memulai sebelum orang } \\
\text { memulai terlebih dahulu, dan } \\
\text { jangan sebab karena kita, } \\
\text { pakailah sifat sabar dan kalau } \\
\text { udah habis sabar maka amarah } \\
\text { tidak bisa lagi di elakan. } \\
\text { Gerakan waw ini kalau kita } \\
\text { mundur kita akan kalah atau } \\
\text { bakalan resiko cedera bagi } \\
\text { kita, dan kalau kita ingin maju } \\
\text { tunggu dahulu orang datang } \\
\text { dan baru kita mulai atau maju } \\
\text { untuk itulah gerakan } \\
\text { serangannya, } \\
\text { waw yang inti sari dari silek } \\
\text { tuo. }\end{array}$ \\
\hline
\end{tabular}

Sumber: Data Lapangan, 2019

Sebenarnya gerakan dasar pada

silek Tuo Gunuang terdiri dari 3 bentuk

gerakan utama, yakni alif, ra, dan waw.

Bukan sekedar sebuah gerakan silek saja,

di dalamnya terkandung maksud dan

tujuan yang bernilai positif.
Gerakan alif ini adalah sebagai tanda memintta izin kepada sang pencipta yaitu Allah supaya sebelum kita memulai dalam hal apapun baik itu dalam permainana atau latihan pergerakan silek kita di lindungi dan di Ridhoi oleh Allah 
supaya gerakan kita ini dalam latihan tidak ada mencelakai orang lain apalagi diri kita sendirinya nantinya. Gerakan alif sama halnya dengan kita berserah diri dan menyerahkan semuanya kepada Allah dan kita memang yakin apapun yang terjadi kedepannya kita telah percaya bahwasanya itu datangnya dari Allah. Gerakan alif ini satu tangan berada di atas dan kepala kita merunduk kebawah itu menandakan kita meminta izin atau berdoa kepada Allah kemudian dalam gerakan tangan yang berada di perut itu mengibaratkan kita untuk melindungi badan bagian depan dari serangan lawan dan menjaganya karena disana merupakan sitem tubuh yang sangat penting karena organ-organ vital itu berada disana, oleh sebab itu tangan itu di artikan untuk menjaga dan melindunginya dari serangan lawan. Gerakan alif ini selain tangan ke atas dan kebawah dalam gerakan alif kaki bagian kanan itu di injit dan di dekatkan dengan kaki kiri dan injitannya semata kaki, gerakan alif ini menandai kita seperti berdoa dan meminta pelindungan agar musibah atau hal yang tidak kita ingin tidak terjadi, oleh sebab itu kepala merunduk kebawah menandakan kita berserah diri seperti orang yang lagi berdoa dan kenapa tidak menghadap ke atas itu menurut informan mendakan keangkuhan kita dalam meminta ke Allah, oleh sebab itu merunduk kebawah tanda kita memang betul-betul berserah diri untuk meminta perlindungan dan keselamatan.

Gerakan ra ini mengikuti kata Nabi atau mengiringi sifat atau tingkah laku serta mengikuti sunnah Nabi atau Rasul, gerakan $r a$ ini berpedoman akan Sunnah Nabi dan Rasul. Dalam gerakan $R a$ ini posisi tangan satu menghambat atau di letakan di perut dan ini bertujuan untuk melindungi bagian badan depan supaya tidak berkibat fatal ke kitanya, dan tangan stu lagi di letakan di arah depan badan untuk menghambat lawan atau menahan lawan untuk tidak melakukan serangan atau kita untuk menyadarkan lawan supaya tidak melakukan hal yang berlebihan. Tegak $r a$ ini di ibaratkan dengan menunggu atau menyuruh lawan untuk bersabar dan untuk mengingatkan 
diri kita untuk bersabar dan tidak berbuat mencelakai terlebih dahulu atau menahan diri. kunci dari ra ini adalah kesabaran kita dan menahan diri untuk tidak berbuat berlebihan.

Gerakan waw ini adalah gerakan yang kesabarannya ada batasnya, dimana titik sabar tidak ada lagi batasnya, gerakan waw ini merupakan gerakan untuk melampiaskan semua kesabaran yang telah kita tahan dan tidak bisa untuk di tahan lagi. Gerakan waw ini merupakan gerakan untuk memulai serangan dan melepaskan semua amarah yang telah kita tahan. Makanya gerakan waw ini di miringkan badannya ke kanan dan di condongkan ke belakang sedikit.

\section{Busana}

Busana dalam silek merupakan unsur yang tidak dapat ditinggalkan. Ada berbagai macam bentuk serta warna yang seluruhnya memiliki makna tersendiri. Namun, soal busana ini tidak ada ketentuan baku yang mengatur penggunaan baju. Lazimnya baju tersebut berwarna gelap dan tidak harus menggunakan bahan tertentu.

Busana atau baju yang digunakan untuk basilek haruslah berwarna hitam keseluruhan yang dimaksudkan untuk meredam emosi atau kita harus sabar dalam segala hal, dalam diri atas perkataan banyak orang kepada diri si pasilek yang sifatnya merendahkan atau memancing kemarahan. Penggunaan baju berwarna hitam agar tidak terlihat banyaknya darah atau kekotoran yang terjadi apabila sedang basilek. Baju hitam dinilai aman yang selain bisa menutupi diri dan meredakan amarah juga aman untuk menutupi dari kekotoran yang jelas. Maksud warna hitam adalah menutup diri untuk tidak melakukan segala sesuatu yang menimbulkan kerugian terhadap diri sendiri. Menutup amarah tidak membicarakan orang lain dan membuatnya tersinggung. Sebagai sesama tentu dalam pergaulan kita harus santun tidak melakukan banyak hal yang bisa membuat hati seseorang tersakiti untuk menciptakan kedamaian dan ketentraman hidup bermasyarakat. 


\section{Tempat Pelaksanaan}

Tempat atau sasaran pada silek tuo gunuang merupakan suatu kerahasiaan. Biasanya dibuat di belakang rumah dengan sepetak tanah yang dibasahi oleh air agar tidak terlalu keras. Tempat adalah bagian yang penting dan turut menentukan keberhasilan silek. Apabila tempat dibuat tanpa perhitungan dan tidak tepat maka akan sulit bagi pemain silek untuk memperagakan gerakan.

Tempat pelaksanaan silek Tuo Gunuang di genangan lumpur adalah ajang silahturahmi. Banyak sekali kesenian Minangkabau yang hendak dan sudah punah padahal secara makna sangat berfungsi untuk menjaga keharmonisan masyarakat. Budaya-budaya yang hampir hilang tersebut perlu untuk dilestarikan kembali agar generasi dan masyarakat luas bisa mengenal ataupun mempelajari silek Tuo Gunuang. Pengenalan atau pelestarian budaya tidak harus benarbenar sama persis seperti aturan normatifnya, penyesuaian dengan kebutuhan zaman juga tidak menjadi masalah yang berarti. Terpenting dari itu semua adalah tetap terpelihara dan eksis hingga waktu yang tidak ditentukan sebagai seni khas Minangkabau.

\section{Simpulan}

Syarat dan unsur-unsur yang terdapat pada silek Tuo Gunuang memiliki makna tersendiri yang berkekuatan untuk memelihara kesatuan masyarakat Minangkabau khusunya. Pada faktanya, unsur tersebut menjadi media berkomunikasi antara individu dengan sesama dalam masyarakat maupun individu dengan Tuhan Yang Maha Esa sang maha pencipta manusia. Demikian halnya dengan syarat-syarat yang harus dipenuhi, keseluruhannya mengandung makna yang berfungsi untuk menjaga hubungan antar sesame manusia maupun dengan penciptanya.

\section{Daftar Pustaka}

\section{Moleong, L. J. 2002. Metode Penelitian Kualitatif. Bandung: Remaja Rosdakarya.}

Naim, M. 1979. Merantau: Pola Migrasi Suku Minangkabau. Yogyakarta: Gadjah Mada University Press. 
Navis, A. 1984. Alam Terkembang Jadi Guru: Adat dan Kebudayaan Minangkabau. Jakarta: Grafiti Press.

Nugroho, O. C. 2015. “Interaksi Simbolik Dalam Komunikasi Budaya (Studi Analisis Fasilitas Publik Di Kabupaten Ponorogo)". Jurnal Aristo Vol.3 No.1 Januari, 1-18.

Putri, D. P. 2015. "Makna Simbolik Randai Sebagai Kesenian Masyarakat Minangkabau di Kota Payakumbuh Provinsi Sumatera Barat". Jom Fisip.

Sunarto, K. 2004. Pengantar Sosiologi (Edisi Revisi). Jakarta: Fakultas Ekonomi Universitas Indonesia.

Suyanto, B. 2005. Metode Penelitian Sosial: Berbagi Alternatif Pendekatan. Jakarta: Kencana Prenada Media Group. 